\title{
Threat Artificial Intelligence and Cyber Security in Health Care Institutions
}

\author{
Ana Fernandes $(\mathbb{D}$, Margarida Figueiredo $\mathbb{D}$, Filomena Carvalho $(\mathbb{D}$, \\ José Neves (i), and Henrique Vicente 1 -
}

\begin{abstract}
In this work we go beyond what is called unsupervised learning, a decision-making method that results in large numbers of false positives and negatives. The study was carried out in cryopreservation laboratories and aims to gain access to the General Data Protection Regulation (GDPR) implementation. Indeed, on the one hand, using Threat Artificial Intelligence, Chaos, Entropy and Security $(T A I C E \& S)$ based methodology for problem solving one may mimic behaviors that are similar to the best human analysts. With the entry into force of the GDPR in the health institutions of the European Union (EU), stronger rules (TAICE based) on data protection (Security) mean people have more control over their personal data and businesses benefit from a level playing field. To respond to this challenge, a workable tool had to be built exploring the dynamics between TAICE\&S and Logic Programming for Knowledge Representation and Reasoning, leading to the implementation of an agency based on TAICE/Cyber Security based techniques for problem solving,
\end{abstract}

A. Fernandes $\cdot$ H. Vicente $(\bowtie)$

Departamento de Química, Escola de Ciências e Tecnologia, REQUIMTE/LAQV, Universidade

de Évora, Évora, Portugal

e-mail: hvicente@uevora.pt

A. Fernandes

e-mail: anavilafernandes@gmail.com

M. Figueiredo

Departamento de Química, Escola de Ciências e Tecnologia, Centro de Investigação em Educação e Psicologia, Universidade de Évora, Évora, Portugal

e-mail:mtf@uevora.pt

F. Carvalho

Departamento de Ciências Jurídicas, Escola Superior de Tecnologia e Gestão, Instituto Poltécnico de Leiria \& Centro de Investigação IJP_-Instituto Jurídico Portucalense, Leiria, Portugal

e-mail: filomena.carvalho@ipleiria.pt

J. Neves

Instituto Politécnico de Saúde do Norte, CESPU, Famalicão, Portugal

e-mail: jneves@di.uminho.pt

J. Neves · H. Vicente

Centro Algoritmi, Universidade do Minho, Braga, Portugal

(C) The Author(s), under exclusive license to Springer Nature Switzerland AG 2021

S. Misra and A. Kumar Tyagi (eds.), Artificial Intelligence for Cyber Security: Methods, Issues and Possible Horizons or Opportunities, Studies in Computational Intelligence 972, https://doi.org/10.1007/978-3-030-72236-4_13, 24 pp. 
which is consistent with an Artificial Neural Network approach to problem definition. It is therefore possible to provide a full-bodied TAICE method to assist in threat identification and evaluation, activity prediction, mitigation, and response strategies. Using TAI procedures, one may identify patterns and matches in the activity of threat players, that combined with the issues of Chaos and Entropy gives us an opportunity to mimic how qualified specialists react in scenarios where models break off.

Keywords Threat artificial intelligence $\cdot$ Chaos $\cdot$ Entropy $\cdot$ Security $\cdot$ Logic programming $\cdot$ Knowledge representation and reasoning $\cdot$ Artificial neural networks 